\title{
2013 年度影响世界的科学人物 一专访陈化兰研究员
}

2013 年 12 月 19 日, Nature 杂志评选的 2013 年度十大科 学人物揭晓 ${ }^{[1]}$, 我国科学家陈化兰作为其中唯一的中国科学 家当选. 这是 Nature 杂志自 2011 年起第 3 次举办的人物评选, 今年遴选的是 2013 年度有重大影响的科学人物.

陈化兰研究员现任中国农业科学院哈尔滨兽医研究所农 业部动物流感重点开放实验室主任, 国家禽流感参考实验室 主任, 世界动物卫生组织(OIE)禽流感参考实验室主任等职务, 是中国第一位 $\mathrm{OIE}$ 专家. 多年来致力于动物流感, 特别是禽 流感的流行病学、诊断技术、新型疫苗研制、分子演变及分 子致病机制等方面研究, 取得了一系列重要研究成果, 研制 的系列禽流感疫苗已经在多个国家的禽流感防控活动中累计 应用 1000 多亿份.

Nature 杂志此次评选将其誉为“流感前线的侦探”, 认为

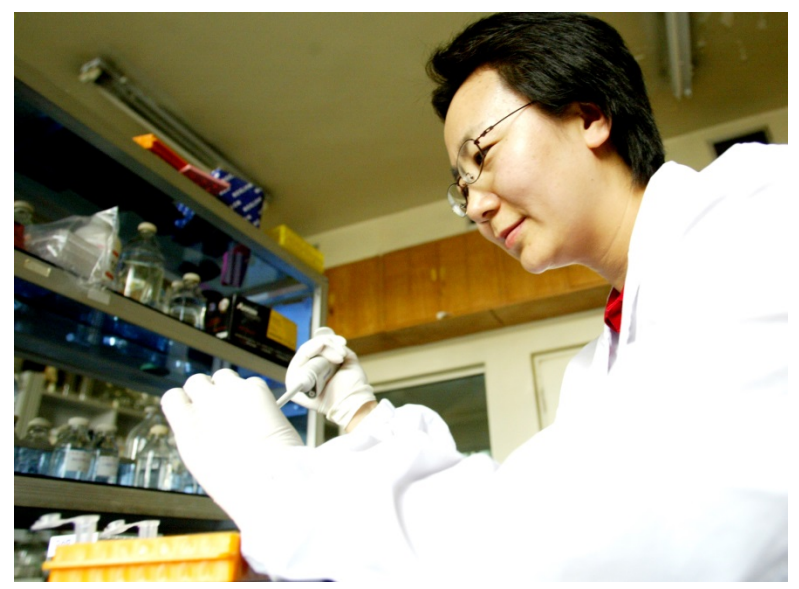
她在 2013 年帮助中国政府有效抑制 H7N9 型禽流感在人际间传播的大规模爆发方面做出了突出贡献.

2013 年 3 月 31 日, 国家卫生和计划生育委员会通报了上海市和安徽省人感染 H7N9 亚型禽流感病毒的疫情, 陈化兰 研究员领导的国家禽流感参考实验室做出快速反应, 在 48 小时内深人上海、安徽的活禽市场和养殖场采集病原学样品进 行检测, 迅速查明该新型 H7N9 病毒的来源, 并立即建议政府部门关闭了一些可能成为病毒源头的活禽市场, 以切断病 毒传播的来源. 通过采取这些行动, 新发的感染病例迅速下降, 传播疫情得到控制, 中国快速而透明的反应措施得到了 广泛赞许, 该项研究为中国政府在关键时刻做出正确决策提供了科学支持, 实现了重大的社会价值.

与这项研究相关的名为“Isolation and characterization of H7N9 viruses from live poultry markets - Implication of the source of current H7N9 infection in humans” "[2]的论文, 发表于《科学通报》英文版(Chinese Science Bulletin)2013 年第 16 期. 文章介绍了上海和安徽人感染 H7N9 病毒早期溯源的研究工作, 从病原学角度揭示了新型 H7N9 流感病毒的来源, 是国际 上首次在活离市场分离到 H7N9 病毒的报告, 为我国科学防控 H7N9 型禽流感提供了重要依据.

《科学通报》编辑部于 4 月 12 日收到了这篇以陈化兰和李呈军共同担任通讯作者的研究论文, 通过“快速通道”评审, 仅用了 6 天时间就完成了稿件的在线发表，随后该研究引起了国内外同行及社会各界的广泛关注.

近期, 《科学通报》对陈化兰研究员进行了采访. 谈到当时选择将最新的成果首先投给《科学通报》的初衷时, 陈化 兰研究员指出, 对 H7N9 病毒的研究是一项非常系统的工作, 相关成果分别发表在 Chinese Science Bulletin 和 Science 杂 志. 首先向《科学通报》投稿的原因, 一是希望可以使稿件快速见刊, 二是希望通过稿件的影响力可以提高中国科技刊物 的被关注度和引用率.

当被问及当选年度十大科学人物的感想时，陈化兰研究员表示，根据“Nature 杂志年度十大科学人物”的评选依据， 认为因对 H7N9 病毒研究的贡献而获此荣誉是她应该得到的认可.

陈化兰研究员介绍说, 她领导的实验室是国家离流感研究的专门实验室, 也是世界动物卫生组织和联合国粮农组织 的参考实验室和参考中心. 面对流感不断变化的新疫情, 其团队未来的重点研究方向是掌握动物流感病毒的生态学、对 动物和人类的风险分析及对动物流感的防控技术研究, 因为“流感病毒监测是实验室的首要任务”.

1365 days: Nature's 10. Nature, 2013, 504: 357-365

2 Shi J Z, Deng G H, Liu P H, et al. Isolation and characterization of H7N9 viruses from live poultry markets-Implication of the source of current H7N9 infection in humans. Chin Sci Bull, 2013, 58: 1857-1863 